\title{
The late prognosis of perforated duodenal ulcer
}

\author{
A. C. B. DEAN, ${ }^{1}$ C. G. CLARK, AND A. H. SINCLAIR-GIEBEN \\ From Aberdeen Royal Infirmary and the Department of Mental Health, \\ University of Aberdeen
}

SYNOPSIS One hundred and seventy cases of perforated duodenal ulcer have been followed up after eight to 10 years. Simple suture of the perforation is recommended. The decision to perform elective surgery is best made during the first two years after perforation rather than at the time of the emergency procedure.

Three methods of immediate treatment of perforated duodenal ulcer are currently employed, namely, simple suture of the perforation, immediate partial gastrectomy (Yudine, 1939; Lowdon, 1952), and conservative treatment (Taylor, 1957). The departure from the traditional method-simple suture of the perforated ulcer-has arisen from doubts about the immediate and late prognosis after this treatment. In view of the conflicting information on late prognosis obtained from consulting the literature, we felt that it would be of value to follow up a reasonably large number of cases eight to 10 years after treatment of a perforated duodenal ulcer by simple suture.

\section{METHODS}

The records of all patients admitted to Aberdeen general hospitals with perforated peptic ulcer were obtained for the years 1950 and 1952 . Records for 1951 were incomplete, so patients treated during this year were excluded from the follow-up.

An attempt was made to trace all patients who survived operation, and they were asked to attend for an interview either at Aberdeen Royal Infirmary or at one of a number of cottage hospitals. Each patient was interviewed by a surgeon, and then seen by the psychiatrist (A.H.S-G.), who assessed the occurrence of psychiatric symptoms during the course of the ulcer history. The psychiatric aspects are reported in a separate paper (Sinclair-Gieben, Clark, and Dean, 1962). Those patients who could not attend for interview were asked to reply to a simple questionnaire.

The patients were assessed as follows:-(a) Completely symptom free; (b) mild or moderate symptoms of recurrent dyspepsia, easily controlled by diet or by alkali; (c) severe symptoms sufficient to justify elective surgery; (d) patients who had undergone elective surgery

'Present address: Department of Surgery, King's College Hospital Medical School, London, S.E.5. such as partial gastrectomy. The results of this operation were classified as excellent, good, fair, or poor.

In the years 1950 and 1952, 242 cases of perforated peptic ulcer were admitted. Table I shows the numbers traced and followed up. Of 203 cases available for follow-up, information was obtained in $175(86 \%)$.

TABLE I

DETAILS OF THE FOLLOW-UP

\begin{tabular}{lc} 
& No. \\
\hline Total number of perforations & $242(100 \%)$ \\
Post-operative deaths & $20(8 \%)$ \\
Subsequent deaths & $19(8 \%)$ \\
Number available for follow-up & $203(100 \%)$ \\
Attended interview & 133 \\
Replied to questionnaire & $42\} 175(86 \%)$ \\
Untraced & $28(14 \%)$
\end{tabular}

The age and sex distribution of the patients is shown in Fig. 1. There were five cases of perforated gastric ulcer, four males and one female. One woman with a perforated duodenal ulcer was found at subsequent partial gastrectomy to have developed a large gastric ulcer. Duodenal and gastric ulcers differ in many important respects and since the number of cases of perforated gastric ulcer is small, they have been excluded from the series and are briefly summarized at the end of the section. Of the 170 patients with a perforated duodenal ulcer, 152 were assessed psychiatrically.

\section{RESULTS}

The ultimate fate of the 170 patients with perforated duodenal ulcer after eight to 10 years is shown in Table II. Sixty-eight patients had undergone elective surgical procedures, and in another 18 cases symptoms were sufficiently severe to warrant this; 36 patients had mild or moderate symptoms and 48 were completely symptom free. 


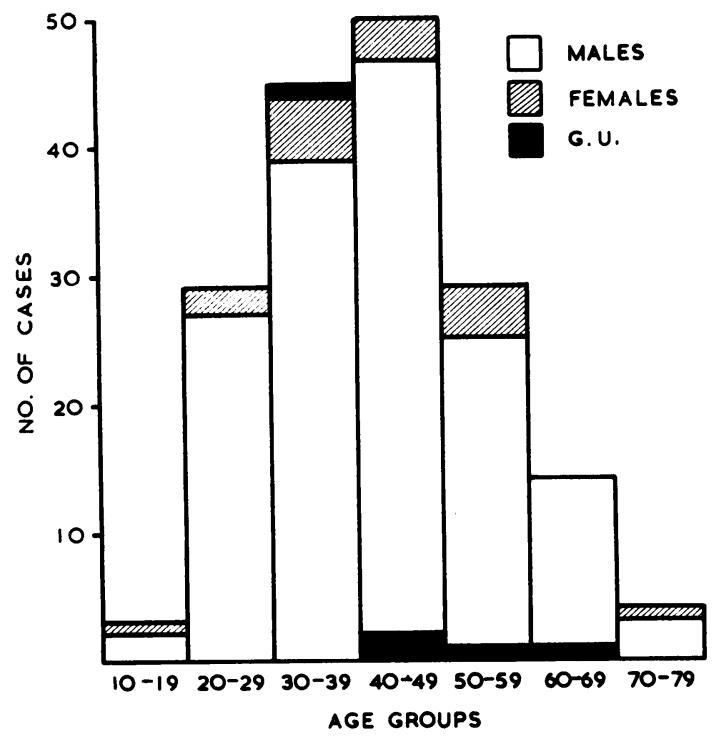

FIG. 1. The age and sex distribution of the 175 cases of perforated ulcer, five cases being gastric in situation (G.U.)

TABLE II ,

LATE PROGNOSIS OF PERFORATED DUODENAL ULCER

No.

Patients with no symptoms

Patients with mild or moderate symptoms $\quad 36(21 \%)$

Patients requiring elective surgery $\quad 18(11 \%)$

Patients who had elective surgery $\quad 68(40 \%)$ Total $170(100 \%)$
The prognosis of the patients was then related to their age at the time of perforation. Table III shows that there is little difference in the percentage of patients in the different age groups who eventually had elective surgery, but of those under 30 years of age, a smaller proportion ( $16 \%$ ) had remained completely symptom free. This supports the widely held opinion that patients who perforate at an early age have a poorer prognosis.

Table IV shows that the duration of symptoms before perforation has a more important effect on the final outcome. The shorter the history, the better the prognosis. Of patients with ulcer symptoms for 10 or more years before perforation, $62 \%$ required elective surgery. The mean age for each group is similar.

In Table $\mathrm{V}$, the number of patients who perforated in each decade is correlated with the mean duration of symptoms before perforation. Patients who perforated before the age of 30 years had a relatively short history. This is to be expected since ulcer symptoms rarely start before the age of 15 . The greatest number of perforations occurred in the 40 to 49 years age group. It is interesting to study the picture in Table $\mathrm{V}$ where the number of patients whose symptoms started in each decade is correlated with the number of years which elapsed before perforation. We see that the maximum incidence of onset of symptoms is in the 20 to 29 years age group, but these patients tended to go for a longer period before perforation occurred. When ulcer symptoms arose in older patients, perforation occurred after a shorter period.

TABLE III

PROGNOSIS RELATED TO AGE AT PERFORATION

\begin{tabular}{rrrrrr}
$\begin{array}{l}\text { Age at } \\
\text { Perforation }\end{array}$ & $\begin{array}{l}\text { No. } \\
\text { Symptom Free }\end{array}$ & $\begin{array}{l}\text { No. with } \\
\text { Mild or Moderate Symptoms }\end{array}$ & $\begin{array}{l}\text { No. with } \\
\text { Severe Symptoms }\end{array}$ & $\begin{array}{l}\text { No. with } \\
\text { Elective Surgery }\end{array}$ \\
\hline $10-29$ & $5(16 \%)$ & $10(31 \%)$ & $4(12 \%)$ & $13(41 \%)$ \\
$30-39$ & $11(25 \%)$ & $5(11 \%)$ & $8(18 \%)$ & $21(46 \%)$ & Total \\
$40-49$ & $19(40 \%)$ & $9(19 \%)$ & $2(4 \%)$ & $17(37 \%)$ & 32 \\
$50-59$ & $6(21 \%)$ & $7(25 \%)$ & $3(11 \%)$ & $12(43 \%)$ & 57 \\
$60-79$ & $7(39 \%)$ & $5(28 \%)$ & $1(5 \%)$ & $5(28 \%)$ & 18 \\
Total & 48 & 36 & 18 & 68 & 170
\end{tabular}

TABLE IV

PROGNOSIS RELATED TO DURATION OF SYMPTOMS BEFORE

PERFORATION

\begin{tabular}{|c|c|c|c|c|c|c|}
\hline $\begin{array}{l}\text { Duration of Symptoms } \\
\text { before Perforation }\end{array}$ & Mean Age & $\begin{array}{l}\text { No. } \\
\text { Symptom Free }\end{array}$ & $\begin{array}{l}\text { No. with Mild or } \\
\text { Moderate Symptoms }\end{array}$ & $\begin{array}{l}\text { No. with } \\
\text { Severe Symptoms }\end{array}$ & $\begin{array}{l}\text { No. with } \\
\text { Elective Surgery }\end{array}$ & Total \\
\hline $\begin{array}{l}0-3 \mathrm{mth} . \\
3 \mathrm{mth} .-1 \mathrm{yr} . \\
1-5 \mathrm{yr} . \\
5-10 \mathrm{yr} . \\
10 \mathrm{yr} .\end{array}$ & $\begin{array}{l}40 \cdot 4 \\
42 \cdot 5 \\
41 \cdot 1 \\
38 \cdot 2 \\
46 \cdot 4\end{array}$ & $\begin{array}{c}23(62 \%) \\
7(41 \%) \\
13(33 \%) \\
3(14 \%) \\
2(3 \%)\end{array}$ & $\begin{array}{r}8(22 \%) \\
2(12 \%) \\
7(18 \%) \\
6(27 \%) \\
13(24 \%)\end{array}$ & $\begin{array}{l}1(3 \%) \\
1(6 \%) \\
5(13 \%) \\
5(23 \%) \\
6(11 \%)\end{array}$ & $\begin{array}{r}5(13 \%) \\
7(41 \%) \\
14(36 \%) \\
8(36 \%) \\
34(62 \%)\end{array}$ & $\begin{array}{l}37 \\
17 \\
39 \\
22 \\
55\end{array}$ \\
\hline Total & & 48 & 36 & 18 & 68 & 170 \\
\hline
\end{tabular}


TABLE V

DURATION OF SYMPTOMS BEFORE PERFORATION RELATED TO AGE AT PERFORATION AND AT ONSET OF SYMPTOMS

\begin{tabular}{lrrrrr}
$\begin{array}{l}\text { Age at } \\
\text { Perforation }\end{array}$ & $\begin{array}{l}\text { No. Mean Duration } \\
\text { of Symptoms } \\
\text { before Perforation } \\
\text { (yr.) }\end{array}$ & $\begin{array}{l}\text { Age at } \\
\text { Onset of } \\
\text { Symptoms } \\
(y r .)\end{array}$ & $\begin{array}{l}\text { No. } \\
\text { (yr.) }\end{array}$ & \multicolumn{2}{c}{$\begin{array}{l}\text { Mean Duration } \\
\text { from Onset } \\
\text { to Perforation } \\
\text { (yr. ) }\end{array}$} \\
\hline $10-19$ & 3 & $0 \cdot 8$ & $10-19$ & 23 & 13 \\
$20-29$ & 29 & $3 \cdot 0$ & $20-29$ & 51 & $9 \cdot 8$ \\
$30-39$ & 45 & $8 \cdot 3$ & $30-39$ & 39 & $6 \cdot 8$ \\
$40-49$ & 47 & $10 \cdot 9$ & $40-49$ & 30 & $2 \cdot 5$ \\
$50-59$ & 28 & $9 \cdot 4$ & $50-59$ & 14 & $1 \cdot 3$ \\
$60-69$ & 14 & $5 \cdot 7$ & $60-69$ & 12 & $2 \cdot 3$ \\
$70-79$ & 4 & $15 \cdot 9$ & $70-79$ & 1 & 1
\end{tabular}

It is evident that although the age of the patient and the duration of symptoms before perforation are important, there may be great difficulty in forecasting the prognosis in the individual case.

\section{ILLUSTRATIVE CASES}

CASE 1 D.L., a banker, began to have typical ulcer symptoms at the age of 32 . Fifteen years later he had a perforated duodenal ulcer. He has remained completely symptom free following simple suture in $\mathbf{1 9 5 0 .}$

CASE 2 J.H., a shipwright, had mild dyspepsia for two weeks before he perforated at the age of 30 . He was completely free of symptoms until two weeks before he perforated again three years later. He has remained symptom free for the last five years.

In Fig. 2 there is a year-by-year assessment of

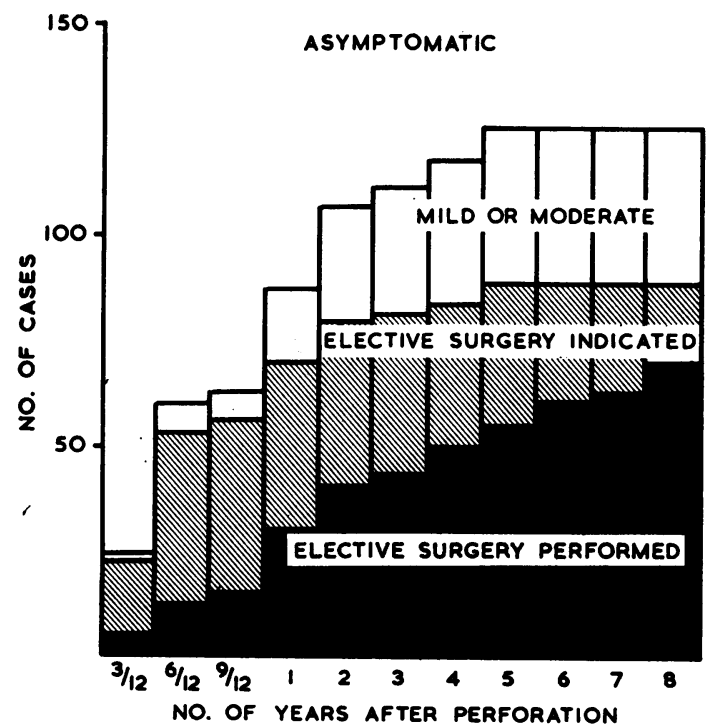

FIG. 2. Year by year progress of the patients showing severity of symptoms and time of recurrence, with ultimate fate of the patient eight to 10 years after perforation. the 170 patients after simple closure of the perforation. Three months after perforation 145 patients were symptom free but this number steadily decreased until, at five years, only 48 were asymptomatic. After this time there was no change in the number who remained symptom free. Similarly, after five years there was no change in the number of patients whose symptoms were severe enough to warrant elective surgery; but it can be seen that almost all of them had developed these severe symptoms within two years of the perforation.

Two or more complications (perforation or bleeding) in the course of a patient's ulcer history are generally regarded as an indication for elective surgery but this may not apply in the case of acute ulcers. Eleven $(6 \%)$ of our patients had a further perforation after the one in 1950-52, and $17(10 \%)$ had previously perforated on at least one occasion.

Two patients had four perforations each, and three, three perforations. Eight had no ulcer symptoms except for a few days before each perforation, including one who had perforated four times.

Twelve $(7 \%)$ had a significant haemorrhage after simple suture of the perforated duodenal ulcer, five requiring emergency surgery. Seven cases had had a major haemorrhage before the perforation. Fig. 3 shows the number of years between complications in all patients who suffered from more than one complication, and it is seen that $50 \%$ of these patients bled or perforated again within two years.

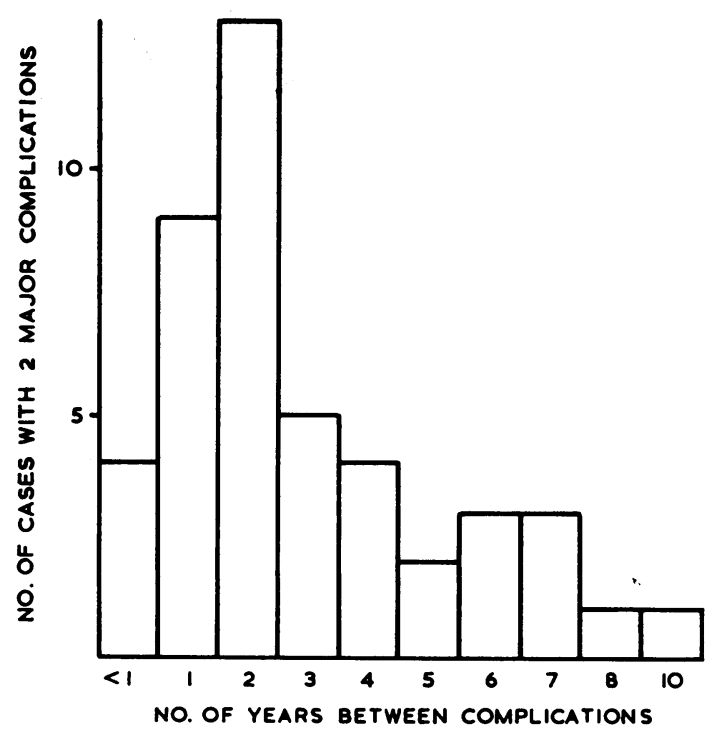

FIG. 3. The number of years after perforation or major haemorrhage at which a second serious complication occurred. 
The true incidence of multiple perforations is always difficult to assess because the population at risk is often unknown. The reported incidence varies greatly; for example, Pearse (1932) estimated it as $0.69 \%$, DeBakey $(1940)$ as $1.1 \%$, Ulfelder and Allen (1942) as $2.7 \%$, and Estes and Bennett (1944) as $15.1 \%$. In our series, $28(16.5 \%)$ had suffered multiple perforations, but this gives an erroneous impression. A more accurate statement is that 11 patients out of 129 presenting with a perforated ulcer as the first major complication of ulcer dyspepsia perforated for a second time within eight years, i.e., $8.5 \%$. Even this is a high incidence and may represent a regional peculiarity.

Sixty-eight patients have had either partial gastrectomy or gastroenterostomy. The results of these operations are shown in Table VI.

TABLE VI

RESULTS OF ELECTIVE SURGERY

\begin{tabular}{lccccc} 
& Excellent & Good & Fair & Failed & Total \\
\hline $\begin{array}{l}\text { Polya gastrectomy } \\
\text { Vagotomy and }\end{array}$ & 48 & 9 & 4 & 2 & 63 \\
gastroenterostomy & 2 & - & - & - & 2 \\
$\begin{array}{l}\text { Gastroenterostomy } \\
\text { alone }\end{array}$ & 2 & 1 & - & - & 3 \\
Total & 52 & 10 & 4 & 2 & 68
\end{tabular}

Twenty patients died after operation for the initial perforation, a mortality of $8 \%$. Of the 19 patients who died after discharge from hospital, two died after partial gastrectomy and two died with further complications related to the ulcer. In nine cases, death was due to causes unrelated to peptic ulcer and in seven the cause of death was not definitely established. These figures include both gastric and duodenal ulcers.

Only five cases of perforated gastric ulcer were seen in this follow-up. Three men had perforated at the ages of 49,57, and 63 years after dyspeptic symptoms lasting 24,10 , and two years respectively. All had been treated by partial gastrectomy with excellent results. One woman who perforated at the age of 32 without any history of dyspepsia and one man who perforated at the age of 48 after a history of two years, have remained sympton free following suture of the perforation.

\section{DISCUSSION}

Aberdeen general hospitals serve a population of approximately 400,000 and almost without exception all acute surgical emergencies in the region were admitted here in the period under review. Regional variation in the incidence of peptic ulcer is well known. In north east Scotland the ratio of duodenal ulcer to gastric ulcer in patients with perforated peptic ulcer is 16.8/1 (Webster and Weir, 1958). The small number of gastric ulcers has not been included in this series, and our observations apply only to duodenal ulcer.

It is accepted that a perforated acute ulcer has a better late prognosis than a perforated chronic ulcer. What is an acute ulcer? Gilmour (1953) described more than $50 \%$ of his series as acute ulcers judged by the appearance at operation. Lowdon (1952) studied the histology of perforated ulcers treated by partial gastrectomy and found that patients with a history of less than one month tended to have acute ulcers. Taylor (1957) has taken a history of less than three months as his criterion for acute ulcers which formed $30 \%$ of his series. Twenty-two percent. of our patients perforated after a history of less than three months, and we have confirmed that they have a better prognosis than all other patients.

Although the late prognosis of perforated duodenal ulcer depends mainly on the duration of symptoms before perforation, it is also influenced by age. Table III shows that patients who perforate before the age of 30 have a poorer prognosis in that fewer remain completely symptom free. This does not imply that patients who develop ulcer symptoms early tend to perforate after a short history, for, as we have shown in Table V, these patients have a mean duration of symptoms of 10 years before the perforation. It is in fact the patients developing symptoms later in life who perforate after a relatively short history.

The number of patients symptom free after perforation decreases with the duration of the follow-up (Illingworth, Scott, and Jamieson, 1946) but we have found that it remains constant after five years. The number of patients whose symptoms are severe enough to warrant elective surgery (86) is also constant at five years but it should be appreciated that the great majority have reached this state within two years of perforation. Of these 86 patients, 80 had severe recurrent symptoms two years after closure of the perforation, although only 48 had been operated on. In many cases in our series the decision to perform elective surgery could well have been made at an earlier stage. Thirteen per cent. of our patients suffered a second major complication after suture of the perforation, and in half of these it occurred within two years. We suggest that all patients with perforated duodenal ulcer be reviewed after two years when a reasonable assessment of the prognosis can be made and an appreciable number of further complications avoided. 
The true incidence of multiple perforations in our series is $8.5 \%$, a higher percentage than is generally recorded. This may be due partly to a regional peculiarity, and it is important to note that eight of our 28 patients with two or more perforations were completely free of symptoms between perforations. These may form a distinct clinical group, and it is interesting to speculate on the justification for elective surgery in a patient whose only disability is an unpredictable liability to perforate.

Fifty-one per cent. of our patients had symptoms requiring elective surgery, compared with $28 \%$ reported by Byrd and Carlson (1956) and 36.5\% recorded by Stabins (1953). Of 68 cases treated by further surgery, excellent and good results were obtained in 62. These results show no significant difference from the results of elective partial gastrectomy for all duodenal ulcer patients recorded in this region (Logie and Clark, 1962). The high incidence of patients requiring elective surgery again suggests a regional difference in the disease and may be related to the small proportion of patients with acute ulcers. It might be taken to support a policy of immediate partial gastrectomy in patients perforating after a long history. We cannot support this view because individual prognosis in our series is so variable. If such a policy had been adopted in patients perforating after a history of two or more years, then some 32 operations (about a third) would, in our opinion, have been performed quite unnecessarily. From our findings we support the policy of the immediate treatment of perforated duodenal ulcer by simple suture. The decision to perform elective surgery in those with severe recurrent symptoms can be made, in the majority of cases, within the first two postoperative years.

\section{SUMMARY}

One hundred and seventy cases of perforated duodenal ulcer have been followed up after eight to 10 years.

Fifty-one per cent. have had or require elective surgery for severe recurrent dyspepsia or further complications.

Patients with a history of less than three months have a good prognosis and represent $22 \%$ of the cases.

Patients whose ulcer symptoms start early in life perforate after relatively long histories.

A policy of immediate simple suture of perforated duodenal ulcer and review during the first two years after operation is advocated.

We would like to thank the consultant surgeons of Aberdeen Royal Infirmary and Woodend General Hospital for permission to study their patients. We are grateful to the matrons of Fraserburgh, Huntly, and Peterhead Hospitals for providing facilities to interview patients. We are particularly grateful for the advice and encouragement given by Professor W. C. Wilson, Mr. N. J. Logie, and Mr. Harold C. Edwards.

\section{REFERENCES}

Byrd, B. F., and Carlson, R. I. (1956). Simple closure of peptic ulcer. A review of end results. Ann. Surg., 143, 708.

DeBakey, M. (1940). Acute perforated gastroduodenal ulceration. A statistical analysis and review of the literature. Surgery, $8,1028$.

Estes, W. L., and Bennett, B. A. (1944). Acute perforation in gastroduodenal ulceration: With special reference to end results. Ann. Surg., 119, 321.

Gilmour, J. (1953). Prognosis and treatment in acute perforated peptic ulcer. Lancet, 1, 870.

Illingworth, C. F. W., Szott, L. D. W., and Jamieson, R. A. (1946) Progress after perforated peptic ulcer. Brit. med. J., 1, 787.

Logie, N. J., and Clark, C. G. (1962). A Follow-up of Cases of Partial Gastrectomy (In preparation).

Lowdon, A. G. R. (1952). The treatment of acute perforated peptic ulcer by primary partial gastrectomy. Lancet, 1, 1270.

Pearse, H. E. (1932). Recurrent perforation of peptic ulcers. Ann. Surg., 96, 192

Sinclair-Gieben, A. H., Clark, C. G., and Dean, A. C. B. (1962). Psychiatric Aspects of the Late Prognosis of Perforated Duodenal Ulcer (In preparation).

Stabins, S. J. (1953). The aftermath of perforated duodenal ulcer. Surgery, 34, 614.

Taylor, H. (1957). The non-surgical treatment of perforated peptic ulcer. Gastroenterology, 33, 353.

Ulfelder, H., and Allen, A. W. (1942). Acute perforation of ulcers of the stomach and duodenum. New Engl. J. Med., 227, 780.

Webster, C. U., and Weir, R. D. (1958). Perforated peptic ulcer in North East Scotland. Scot. med. J., 3, 288.

Yudine, S. (1939). Etude sur les ulcères Gastriques et duodénaux perforés. J. Int. Chir., 4, 219. 